\title{
Comunicación

\section{La responsabilidad de la televisión mexicana en la erradicación de la violencia de género contra las mujeres y las niñas: apuntes de una investigación diagnóstica1}

AIMÉE VEGA MONTIEL2

Este artículo forma parte de la investigación feminista "La influencia de los medios de comunicación en la representación social de la violencia contra las mujeres y las niñas", y tiene el objetivo de compartir una serie de resultados, análisis y reflexiones preliminares derivadas del análisis de contenido de la programación de los principales canales de televisión abierta en el país, que apuntan a la responsabilidad de esta industria en la erradicación de este problema.

PALABRAS CLAVE: mujeres, niñas, derechos humanos, violencia contra las mujeres, televisión.
This article is part of the feminist research "The violence against women and girls in the media agenda: an unsettled task". Its objective is to analyze the results of the analysis of the Mexican television agenda, that show the way this media represents and reproduces this problem. The goal is to call the responsibility of media in the eradication of all forms of violence and discrimination against women and girls.

KEY WORDS: women, girls, human rights, violence against women, television.

1 Esta investigación ha sido desarrollada con el apoyo del Programa PAPIIT de la UNAM in308808, y corresponde al proyecto "La influencia de los medios de comunicación en la representación social de la violencia contra las mujeres y las niñas". Ha contado con la participación de Walys Becerril, Nelly Lara e Hilda Cruz.

2 Centro de Investigaciones Interdisciplinarias en Ciencias y Humanidades-UNAM.

Correo electrónico: aimeevegamx@yahoo.com.mx 


\section{LA VIOLENCIA DE GÉNERO: EL OBSTÁCULO}

PARA LA REALIZACIÓN DE LOS DERECHOS HUMANOS

DE LAS MUJERES Y NIÑAS

La adopción de los estatutos de las Naciones Unidas en 1945 y de la Declaración Universal de los Derechos Humanos en 1948, obligó a los Estados miembros a reconocer, establecer, proteger y fortalecer los derechos humanos a nivel global, regional, nacional y local. Desde entonces, el respeto a la dignidad de las personas y a su derecho a la igualdad ha impulsado a la comunidad internacional a reconocer y asumir su responsabilidad en la promoción, respeto y protección universal de los derechos humanos. Asimismo, a garantizar la indivisibilidad de estos y su interdependencia con la paz y el desarrollo.

Estos derechos, sin embargo, no establecen en sí mismos el principio de universalidad al que la propia Declaración alude pues, expresados en masculino, es decir, apuntando claramente al hombre como sujeto de reconocimiento, los instrumentos jurídicos internacionales, así como los mecanismos de derechos humanos, no contemplaron que su puesta en práctica debía considerar las diferencias entre mujeres y hombres y, por lo tanto, las especificidades, necesidades y demandas de las mujeres. Así, el derecho a ser tratadas con respeto y dignidad, y a gozar, en igualdad de condiciones y oportunidades, de los derechos que disfrutan los hombres, como fue reconocido en la Conferencia Mundial de Derechos Humanos, en Viena, apenas en 1993, pero que continúa siendo, hasta el día de hoy, la asignatura pendiente más importante para la realización de una sociedad pacífica, democrática y desarrollada.

En esta amplia y profunda tarea, el feminismo ha logrado llevar a la agenda mundial de los derechos humanos las problemáticas, demandas y perspectivas de las mujeres, entre las que se encuentran su derecho a la integridad física, a una vida sexual y reproductiva plena y sana, al trabajo y a conservar los ingresos, a poseer un patrimonio, a la educación, a la cultura, a la participación política, al acceso al poder, a la comunicación y la información y, los más importantes, a la vida y a la libertad.

Que se reconozca a este campo como una asignatura pendiente, significa reconocer, al mismo tiempo, la desafortunada constatación de 
que los derechos humanos de las mujeres y las niñas son violentados en todos los ámbitos de su vida por razón de género, es decir, por ser mujeres. En consecuencia, mujeres, derechos humanos y violencia conforman, hasta hoy, un trinomio que no hemos logrado disociar, puesto que la violencia de género contra las mujeres y las niñas constituye el ámbito en el que se concretan las violaciones y, por lo tanto, el impedimento de sus derechos.

En este marco, la reciente aprobación de la Ley General de Acceso de las Mujeres a una Vida Libre de Violencia (Gobierno Federal, 2007), publicada en nuestro país, hace evidente que la violencia de género contra las mujeres y las niñas constituye un problema estructural que, de no ser erradicado, impedirá la realización democrática a la que aspira la sociedad mexicana. ${ }^{3}$

La información que respaldó la urgente necesidad de promover esta ley, es la derivada de la Investigación diagnóstica. Violencia feminicida en la República Mexicana, de la Comisión Especial para Conocer y dar Seguimiento a las Investigaciones Relacionadas con los Feminicidios en la República Mexicana y a la Procuración de Justicia Vinculada (2006), de la LIX Legislatura de la Cámara de Diputados encabezada

3 Esta violencia encuentra como marco la brecha de desigualdad entre mujeres y hombres. En este sentido, Emilio Álvarez Icaza, presidente de la Comisión de Derechos Humanos del Distrito Federal, señala que, según el Informe Mundial sobre Brecha entre Géneros del 2007, México ocupa el lugar 93 de 128. También, que las mujeres en México representan cuatro de cada diez personas que integran la población económicamente activa (PEA), pero sólo 3\% tiene un puesto directivo; $10.45 \%$ de las que se encuentran dentro de la PEA no percibe ingresos. Respecto a los derechos políticos, 23 de los 128 escaños del Senado de la República son ocupados por mujeres, es decir, sólo 18\%; mientras que en cuanto a la toma de decisiones, sólo presiden cinco de 57 comisiones, menos de $10 \%$, cuando constituyen más de la mitad de los electores en el país. En la Cámara de Diputados, 117 curules, de las 500 que hay, son ocupadas por mujeres, apenas 23\%, y presiden ocho de 44 comisiones. México cuenta con 2,439 municipios y delegaciones, pero sólo 85 presidencias municipales están a cargo de mujeres, es decir, en ese ámbito $3.5 \%$ son mujeres (Álvarez, 2008). 
por la antropóloga Marcela Lagarde. ${ }^{4}$ Esta investigación sobre la muerte violenta de niñas y mujeres en el país, documentada en información oficial, 5 ha permitido dar cuenta de las precarias condiciones de vida de la mayoría de las mujeres y de la prevalencia de la violencia de género en todo su ciclo de vida, en todas las clases sociales y en todos los grupos étnicos, conjunto de condiciones que conduce al feminicidio. ${ }^{6}$ Estas formas de violencia se suceden ante la insuficiente e inadecuada atención por parte de las autoridades.

También es desafortunado reconocer que este proceso prevalece en todo el mundo. Numerosas investigaciones desarrolladas por organismos internacionales, por universidades, por instituciones de gobierno y por partidos políticos evidencian que las distintas formas de violencia contra las mujeres se manifiestan a escala mundial. Mujeres de todas las nacionalidades, niveles económicos, educativos y edades parecen compartir una experiencia que viene determinada por su condición de género: la discriminación y la violencia. No importa el país, entorno social, económico, cultural o político particular cuando de identificar los golpes, las humillaciones, el hostigamiento, el abuso sexual y el control económico se trata: es un denominador común en la experiencia vivida de TODAS. Así, aunque la violencia contra las mujeres y las niñas se exprese de formas muy variadas, de acuerdo al contexto y a los diversos medios

4 Esta investigación reunió el trabajo de 80 investigadoras que alrededor del país nos dimos a la tarea de documentar la dolorosa prevalencia de la violencia contra las mujeres, y en particular de la violencia feminicida en México.

5 De los ejecutivos estatales, los institutos de las mujeres, las procuradurías estatales de justicia y autoridades estatales y municipales. También, de los congresos estatales, de los tribunales estatales y del Distrito Federal, de las organizaciones civiles y las instituciones académicas y de los reportes de la prensa (Comisión Especial del Feminicidio, Cámara de Diputados LIX Legislatura, 2006).

6 De acuerdo con Marcela Lagarde (2006), el feminicidio constituye el conjunto de delitos de lesa humanidad que contienen los crímenes, los secuestros y las desapariciones de niñas y mujeres en un cuadro de colapso institucional. Se trata de una fractura del Estado de derecho que favorece la impunidad. El feminicidio es un crimen de Estado. 
que sean empleados para ejecutarla, es posible identificar indicadores comunes que, por ello, permiten afirmar que se trata de un problema universal: las consecuencias físicas, emocionales, psicológicas, económicas y sociales que marcan la experiencia de vida de las mujeres.

Las cifras así lo corroboran: en Estados Unidos, cada año un millón y medio de mujeres son objeto de violencia física o sexual por parte de algún familiar (Now Legal Defense and Education Fund, 2005). En Suecia, una mujer muere cada 10 días en el espacio doméstico por razones de violencia doméstica (Instituto Oficial de Radio y Televisión de España [IORTVE], 2002). En Rusia, en el año de 1993, 14,000 mujeres fueron asesinadas por su marido y 54,000 fueron objeto de maltrato físico y psicológico (Seager, 2001). En España, las cifras oficiales denuncian que la violencia doméstica contra las mujeres alcanza las 25,000 víctimas al año, aunque se afirma que esta cifra representa sólo $10 \%$ de la real (IORTVE, 2002). Y en Canadá el panorama no es menos pesimista, pues $29 \%$ de mujeres son objeto de algún tipo de violencia en el hogar (Seager, 2001).

En los países pobres, la situación se torna más difícil: en India, entre 1988 y 1993, más de 20,000 mujeres fueron asesinadas por esta causa. En Vietnam, 70\% de los divorcios registrados en 1991 encuentran su origen en la violencia, de la cual las mujeres han sido objeto (idem).

Ante la inocultable y universal evidencia de la violencia de género contra las mujeres y las niñas, e impulsados por el movimiento feminista, los organismos internacionales y gobiernos del mundo se han dado a la tarea de emprender acciones dirigidas a erradicarla, al reconocer que su prevalencia, que implica la violación de los derechos humanos de las mujeres, representa un obstáculo para la realización de la paz, la democracia y el desarrollo.

Consecuencia de ello, en 1979 la Asamblea General de la ONU aprobó la creación de la Convención sobre la Eliminación de todas las Formas de Discriminación contra la Mujer, conocida como CEDAW, y constituye el primer instrumento internacional que trata de manera extensa los derechos humanos de las mujeres y que apunta a la violencia como un atentado a su vida, razón por la cual establece claramente el marco jurídico para que todas las formas de discriminación y violencia ejercidas contra ellas sean erradicadas. 
A nivel regional, en 1994 los Estados miembros de la Organización de los Estados Americanos, entre los que se encuentra México, se reunieron en la Convención Interamericana para prevenir, sancionar y erradicar la violencia contra la Mujer, conocida como Convención de Belém Do Pará, la que generó un convenio que los Estados miembros signaron con el compromiso de realizar las recomendaciones señaladas.

En su conjunto, ambos instrumentos jurídicos instan a los Estados a:

1) Promover la formulación de todas las normas penales, civiles y administrativas necesarias para prevenir, sancionar y erradicar las formas de discriminación y de violencia contra las mujeres;

2) Diseñar programas de educación formales y no formales dirigidos a modificar los patrones socioculturales de conducta de mujeres y de hombres;

3) Establecer los mecanismos judiciales y administrativos necesarios para asegurar la protección efectiva de las mujeres que sean objeto de discriminación y de violencia, suministrando los servicios especializados necesarios por medio de entidades de los sectores público y privado;

4) Convocar a los medios de comunicación a elaborar directrices adecuadas de difusión que contribuyan a erradicar este problema;

5) Garantizar la investigación y recopilación de información sobre las causas, consecuencias y frecuencia de la discriminación y la violencia contra las mujeres;

6) Destinar los recursos necesarios para llevar adelante estas acciones.

Un año después, en septiembre de 1995, la Cuarta Conferencia Mundial sobre la Mujer adopta la Declaración de Beijing, y la Plataforma de Acción establece que la eliminación de la violencia contra las mujeres es esencial para la igualdad, el desarrollo y la paz de las naciones. La Declaración de Beijing señala la responsabilidad que las instituciones deben asumir en la erradicación de este problema estructural.

México ha ratificado esos acuerdos, por lo cual la Ley General de Acceso de las Mujeres a una Vida libre de Violencia, publicada en el Diario Oficial de la Federación el 2 de febrero de 2007, y que armoniza con la CEDAW y con Belém Do Pará, representa la oportunidad para que el Estado mexicano asuma su responsabilidad en la eliminación de este problema estructural. 


\section{LA VIOLENCIA DE GÉNERO}

\section{CONTRA LAS MUJERES Y LAS NIÑAS}

Cuando nos referimos a la violencia de género contra las mujeres, recurrimos a concepciones científicas que han sido ampliamente definidas y discutidas por el feminismo, y que son las que sostienen los instrumentos jurídicos a los que hacemos referencia. En este sentido, debemos señalar que uno de los temas fundamentales en la teoría y la agenda de investigación feminista a lo largo de su historia, ha sido la violencia de género contra las mujeres y las niñas, con el objetivo de desmontar las creencias y explicaciones que prevalecen en la sociedad sobre este problema y extirparlo definitivamente.

La violencia de género contra las mujeres y las niñas se puede considerar como la conducta que incluye cualquier agresión física, psicológica, sexual, patrimonial, económica o feminicida, dirigida contra ellas por el hecho de serlo (Lagarde, 2006). Es un tipo de violencia que se produce en un esquema de poderes desiguales, que busca someter y controlar a las mujeres y a las niñas, que las daña y lesiona, y que transgrede sus derechos humanos. En este tenor, el sistema patriarcal que establece y naturaliza jerarquías entre las mujeres y los hombres, que designa al hombre como sujeto de poder y autoridad, y a la mujer como objeto de sometimiento, discrimina y al mismo tiempo violenta sus derechos humanos. En consecuencia, el ejercicio de la discriminación y la violencia contra las mujeres implica la negación de su humanidad, es decir no sólo de sus derechos sino de su existencia.

La violencia contra las mujeres y las niñas es el mecanismo utilizado por los hombres para asegurar el mantenimiento del poder y el disfrute de privilegios. En este sentido, la violencia ha sido articulada en nuestras estructuras e ideologías, y es admitida por una serie de convenciones sociales, leyes e instituciones, al tiempo que es "una forma de hacer negocios", pues reporta enormes beneficios económicos a los hombres (Kaufman, 1999). Junto con el control del poder, la percepción que los hombres tienen de su derecho a privilegios -insultar o golpear a su cónyuge al percibir que es de su propiedad, o acosar e incluso violar a una mujer, al percibir que tiene el privilegio del placer-, están en la base de la violencia. En este marco, la violencia contra las mujeres constituye 
la vía para reestablecer el poder masculino y que los hombres utilizan para afirmar su virilidad frente al mundo. La violencia contra las mujeres y las niñas es, entonces, un mecanismo compensatorio individual para cada hombre, al tiempo que constituye el mecanismo socialmente aceptado para afirmar el control y el poder masculino:

...tal sentimiento sólo exacerba las inseguridades masculinas: si la masculinidad es una cuestión de poder y control, no ser poderoso significa no ser hombre. De nuevo, la violencia se convierte en el medio para probar lo contrario ante sí mismo y ante otros (idem).

Por ello, la urgencia de desmantelar las estructuras de poder y privilegios de los hombres y erradicar el permiso cultural que se les otorga para violentar la vida y dignidad de las mujeres y las niñas. ${ }^{7}$

Los tipos de violencia contra las mujeres y las niñas incluyen:

a) Violencia física: la que se propina al cuerpo y lo marca, dejando huellas internas y externas en él. Se asocia la violencia física con la fuerza, pero no se agota en los daños corporales, pues tiene efectos psicológicos, emocionales y de otra índole.

b) Violencia psicológica: la que perpetra daños a la esfera emocional, que vulnera el derecho a la integridad psíquica. Utiliza la coerción, las amenazas, la intimidación, la humillación, la privación de la libertad, el chantaje y la manipulación. Genera confusión, incertidumbre y miedo, es decir, daños que marcan la salud mental de las mujeres.

c) Violencia sexual: la más evidente es la violación, que usa la fuerza moral y física para someter a la víctima. Es la forma más brutal y contundente de violencia sexual pero no la única. El hostigamiento

7 En este punto es importante aclarar que en la sociedad patriarcal la violencia de los hombres contra las mujeres no sucede en aislamiento, sino vinculada a la violencia de unos hombres contra otros, mecanismo utilizado por ellos desde la niñez para establecer jerarquías. Por ello, no es equivalente el análisis de la violencia contra las mujeres (pues es por razón de género) a la violencia contra las hombres, pues es por razón de la lucha por el poder entre ellos. 
sexual -acoso, burla, sometimiento- es una de las formas más comunes y justificadas de este tipo de violencia. La violencia sexual incluye la violencia física, pues somete al cuerpo, y la psicológica, porque vulnera la integridad emocional de las mujeres.

d) Violencia económica: es la violencia a la disposición efectiva de los valores y al manejo de los recursos materiales de las mujeres, y que transgrede sus derechos (Ley General, 2007).

Además de estos, la Ley General incluye otros tipos de violencia, como la patrimonial, que define como:

Cualquier acto u omisión que afecta la supervivencia de la víctima. Se manifiesta en la transformación, sustracción, destrucción, retención o distracción de objetos, documentos personales, bienes y valores, derechos patrimoniales o recursos económicos destinados a satisfacer sus necesidades y puede abarcar los daños a los bienes comunes o propios de la víctima.

\section{Y la feminicida que:}

Es la forma extrema de violencia de género contra las mujeres, producto de la violación de sus derechos humanos, en los ámbitos público y privado, conformada por el conjunto de conductas misóginas que pueden conllevar impunidad social y del Estado, y puede culminar en homicidio y otras formas de muerte violenta de mujeres.

Una aportación fundamental de esta ley es que identifica tipos de la violencia, a las que define como los ámbitos en los cuales la ejercida contra las mujeres es ejecutada. En este tenor, establece como modalidad la violencia familiar, que:

Es el acto abusivo de poder u omisión intencional, dirigido a dominar, someter, controlar, o agredir de manera física, verbal, psicológica, patrimonial, económica y sexual a las mujeres, dentro o fuera del domicilio familiar, cuyo agresor tenga o haya tenido relación de parentesco por consaguinidad o afinidad, de matrimonio, concubinato o mantengan o hayan mantenido una relación de hecho. 


\section{La laboral y docente, que:}

Se ejerce por las personas que tienen un vínculo laboral, docente o análogo con la víctima, independientemente de la relación jerárquica, consistente en un acto o una omisión en abuso de poder que daña la autoestima, salud, integridad, libertad y seguridad de la víctima, e impide su desarrollo y atenta contra la igualdad.

La comunitaria, que está constituida por "los actos individuales o colectivos que transgreden derechos fundamentales de las mujeres y propician su denigración, discriminación, marginación o exclusión en el ámbito público". Y la institucional, expresada en todos:

Los actos u omisiones de las y los servidores públicos de cualquier orden de gobierno que discriminen o tengan como fin dilatar, obstaculizar o impedir el goce y ejercicio de los derechos humanos de las mujeres, así como su acceso al disfrute de políticas públicas destinadas a prevenir, atender, investigar, sancionar y erradicar los diferentes tipos de violencia. 8

Con base en esta clasificación, que sobre los tipos y las modalidades de la violencia contra las mujeres y las niñas ha construido la teoría feminista, es posible deducir que esta tiene diversas manifestaciones; que se vale de distintos medios y produce distintas consecuencias; que no se limita al maltrato físico o psicológico, pues trasciende a todas las esferas de la vida, y que no se agota en los golpes ni en los daños materiales, pues transgrede también la integridad psicológica, emocional y sexual de las mujeres y las niñas.

Por todo lo anterior, la violencia de género contra las mujeres y las niñas constituye un problema estructural que afecta la habilidad de éstas para participar en proyectos de desarrollo, ejercer su ciudadanía y realizar sus derechos en democracia (Carrillo, 1992; Lori, 1994).

8 Artículos 6, 7, 10, 11, 12, 13, 16, 18 y 20 de la Ley General de Acceso de las Mujeres a una Vida Libre de Violencia, en Diario Oficial de la Federación, $1^{\circ}$ de febrero del 2007 (documento en línea en http://www.diputados.gob. mx/LeyesBiblio/pdf/LGAMVLV.pdf). 


\section{LA RESPONSABILIDAD DE LOS MEDIOS DE COMUNICACIÓN}

EN LA REALIZACIÓN DE LOS DERECHOS HUMANOS DE LAS MUJERES Y LAS NIÑAS: EL MARCO JURÍDICO INTERNACIONAL Y NACIONAL

Los medios de comunicación han sido señalados como una institución que tiene la responsabilidad de erradicar la violencia contra las mujeres $\mathrm{y}$, en consecuencia, contribuir a la realización de los derechos humanos de éstas. Al constituirse como una fuente de educación -formal e informal- para la sociedad, al lado de la familia y de la escuela, tienen una tarea central en la búsqueda de soluciones.

Es en este marco que los organismos internacionales se han dado a la tarea de emitir recomendaciones a los mass media, en aras de que examinen las consecuencias de la reproducción de estereotipos sexistas en su programación, incluidos aquellos contenidos en los anuncios publicitarios que promueven la violencia y la discriminación de género, y de que adopten medidas para eliminar esas imágenes negativas con miras a promover una sociedad basada en los principios de equidad y respeto, esenciales para el desarrollo y la paz de las naciones.

Así también, de generar una conciencia acerca de la responsabilidad que tienen las instituciones mediáticas en la promoción de imágenes no estereotipadas de mujeres y hombres, y de eliminar los modelos de conducta generadores de violencia que en ellos se presentan, así como de alentar a las personas responsables de producir los contenidos a que establezcan directrices y códigos de conducta profesionales. Y, por último, sensibilizar sobre la importante función en lo relativo a informar y educar a la población acerca de las causas y los efectos de la violencia contra las mujeres y a estimular el debate público sobre el tema.

En concreto, las recomendaciones más importantes realizadas por dos instancias fundamentales en este debate -la Plataforma de Acción de Beijing y la Convención Belém Do Pará-, señalan que las industrias audiovisuales tienen el deber de:

1. Adoptar todas las medidas necesarias para eliminar los prejuicios y las prácticas consuetudinarias y de otro tipo, basadas en la idea de inferioridad o la superioridad de uno u otro sexo y de los estereotipos asignados a mujeres y hombres. 
2. Elaborar directrices adecuadas de difusión que contribuyan a erradicar este problema.

Si bien nuestro país ha suscrito estos acuerdos, hasta hace muy poco tiempo no se habían llevado a cabo acciones concretas que alentaran a los medios de comunicación, desde el marco jurídico, a contribuir en la erradicación de la violencia contra las mujeres en todas sus formas y a realizar el respeto a la dignidad de estas. Es la Ley General de Acceso de las Mujeres a una Vida Libre de Violencia la que por primera vez establece de manera clara recomendaciones dirigidas a que los medios se sumen a esta tarea, señalando que estos no deben "fomentar la violencia contra las mujeres y que favorezcan la erradicación de todos los tipos de violencia, para fortalecer el respeto a los derechos humanos y la dignidad de las mujeres".

\section{LOS MEDIOS DE COMUNICACIÓN EN MÉXICO}

Y SU RESPONSABILIDAD EN LA ERRADICACIÓN DE LA VIOLENCIA DE GÉNERO CONTRA LAS MUJERES Y LAS NIÑAS

Con la base señalada, la investigación "La violencia contra las mujeres en la agenda mediática: una asignatura pendiente" tiene como objetivo "analizar y determinar, con perspectiva de género, la representación de la violencia contra las mujeres y las niñas en la agenda mediática en México", a fin de contribuir con la generación de propuestas que promuevan una cobertura y difusión responsable de este problema, de manera que los mass media, y especialmente la televisión, lo eliminen en sus propuestas didácticas y de conciencia social.

Los objetivos particulares que se han establecido, son:

9 Esta investigación se desarrolla en el marco del Programa de Investigación Feminista del CEIICH-UNAM. El trabajo empírico ha sido posible gracias al apoyo de Walys Becerril, asistente de la investigación, y de diez alumnas y un alumno provenientes de distintas universidades públicas del país, que durante el verano de 2007 apoyaron el proyecto en el marco del Programa Verano de la Investigación Científica, de la Academia Mexicana de Ciencias. 
1. Identificar, con una perspectiva feminista, los contenidos mediáticos que abordan la violencia contra las mujeres y las niñas. ${ }^{10}$

2. Determinar, con una perspectiva feminista, el tratamiento que los medios de comunicación realizan de la violencia de género contra las mujeres y las niñas.

3. Corroborar si los medios de comunicación evidencian las desigualdades de género que dan origen a la violencia contra las mujeres y las niñas.

La clave teórica para analizar este proceso comunicativo es la agenda setting, pues representa una herramienta útil para determinar la forma en la cual los medios de comunicación construyen su agenda y contribuyen a reproducir la social en torno al problema que aquí se discute. De acuerdo con McCombs y Shaw (1972), los medios tematizan, ${ }^{11}$ a través de sus contenidos, una agenda que transfiere al público temas que generan opinión y discusión. Sin embargo, al mismo tiempo, esta teoría reconoce que en lo que no pueden influir los mass media es en la construcción de sentido que la sociedad hace de estos temas, pues en este proceso intervienen una serie de mediaciones que van más allá de la agenda mediática, tales como: género, edad, nivel educativo, socioeconómico, contexto sociohistórico, entre otras.

Desde esta perspectiva, podemos conocer la forma y los mecanismos mediante los cuales los medios de comunicación construyen un discurso en torno a la violencia de género contra las mujeres y las niñas.

La unidad de análisis del trabajo empírico está constituida por la representación, una categoría que nos permite comprender los procesos

10 La primera fase de la investigación está centrada en diagnosticar, con base en un análisis de contenido, la agenda de la programación de televisión y radio, así como de las páginas de Internet, periódicos y revistas.

11 Wolf (1994) define a la tematización como un procedimiento informativo, toral en la teoría de la agenda setting. Tematizar un problema significa colocarlo en el orden del día de la atención del público, concederle la importancia adecuada, subrayar su centralidad y su significatividad respecto al curso normal de la información. 
de construcción social de sentido y ubicar, en particular, el proceso mediante el cual los grupos sociales y las instituciones sociales -entre las cuales se encuentran los medios de comunicación-se apropian a la vez que construyen y reproducen significados. Para definirla, ha sido preciso remitirse al campo de las representaciones sociales inaugurado por Moscovici (1976), a las que define como los lugares del conocimiento social que poseen una naturaleza simbólica, y que son construidas a partir de la experiencia del sujeto con su entorno. Las representaciones sociales constituyen un proceso - por lo que no es acabado sino transformable en la vida cotidiana-, de reconstrucción de lo real, de relaciones entre sujetos y sociedad, gracias a las cuales las personas hacen inteligible la realidad. Dichas representaciones tienen al menos cuatro funciones: 1) la de conocimiento, en tanto que posibilitan que el sujeto comprenda y explique la realidad; 2) la identitaria, que permite al sujeto identificarse con un grupo social con el cual comparte normas y valores determinados; 3 ) la de orientación, que aporta claves para que el sujeto estructure sus prácticas y comportamientos, y 4) la justificatoria, que permite al sujeto justificar un comportamiento ante el grupo social (Abric, 1994).

De esta forma, se reconoce a las representaciones sociales en tanto proceso constituido a la vez que constituyente de los imaginarios, las creencias, los conocimientos y las normas sociales (Ibáñez, 1988). ¿Y qué es lo que traducen las representaciones sociales?: el sistema ideológico existente.

En esta línea, el género constituye una representación toral del sistema social al constituirse en lugar en el que se cruzan discursos, creencias y normas sobre lo que la identidad femenina y masculina representan, y sobre la relación de poder que priva entre ambos géneros, que se ha traducido históricamente en la supremacía masculina sobre la subordinación femenina. Esos discursos, estereotipos y creencias se visibilizan en la desigualdad de género que se expresa en la dimensión social, pero también en la económica, la jurídica, la política y la cultural, lo que origina el trato discriminatorio de las mujeres (Flores-Palacios, 1996).

La representación social de género cumple una función fundamental: la de la reproducción del sistema patriarcal mediante la 
socialización y educación de estos discursos. Y esta representación es la que se encuentra en la base de la violencia contra las mujeres, pues naturaliza el castigo y la venganza dañina como derechos legítimos ejercidos sobre ellas, y de ahí que lo veamos como natural; cuando lo vemos.

En este punto, reconocemos que esta representación social es creada y reproducida por las instituciones sociales clave: la familia, la escuela, los gobiernos, los partidos políticos y los medios de comunicación, a través de distintas y variadas tecnologías sociales (De Lauretis, 1987). Por ello, esta investigación se ha situado en el ámbito de las representaciones sociales, que ofrecen la posibilidad de preguntar y responder, como afirma Márgara Millán, "sobre el lenguaje y sus formas, lo que construyen y dejan fuera" (1996, p. 179), y también, acerca de la actuación de los mass media en cuanto a la organización homogeneizadora y dicotomizante de las relaciones de género. En este sentido, se reconoce que los medios de comunicación son pieza clave en la producción de tales representaciones, pues:

Realizan una nominación y organización de lo real (considerada además legítima e institucional) que se arraiga en los modos en que los individuos interpretan y actúan en la sociedad, se estabilizan y refuerzan las relaciones de poder [...] Esto lleva implícita una dominación discursiva de las perspectivas ideológicas que tienen mayor peso en la estructura social: el orden burgués, el orden patriarcal [...] (Pedraza, 2008, p. 41).

De esta forma, la importancia de los medios de comunicación, en el ámbito de las representaciones sociales, se halla en su poder de construir creencias y opiniones que se estructuran como reglas sociales. Desde luego, los medios realizan dichas representaciones apegados a las normas y principios de construcción de la realidad del grupo social; sin embargo, tienen el poder de influir en la conciencia social y, por lo tanto, de transformar la propia realidad.

En particular, es preciso llamar la atención sobre uno de los riesgos que supone la construcción simplificada de la representación social de género por los medios de comunicación: los estereotipos. Si aquellos aluden a las exigencias de producción como condicionante, e incluso como impe- 
dimento para abundar en explicaciones sobre las causas y consecuencias de los problemas sociales - que es como sucede-, entonces pocas posibilidades existen de que se conviertan en vehículo de una transformación social que promueva la igualdad entre mujeres y hombres.

A la vista de lo expuesto, se considera que la representación, como unidad de análisis, posibilita realizar una deconstrucción precisa de las formas, los ámbitos, los sujetos y los objetos que prevalecen sobre la violencia de género contra las mujeres y las niñas en el discurso mediático.

La técnica de investigación que sirve como herramienta de estudio es el análisis de contenido para identificar a los que han sido definidos como ámbitos de la representación:

- Características de la representación: las de los mensajes en los cuales es representada la violencia contra las mujeres.

- Sujetos de la representación: los sujetos e instituciones que son visibilizados en el mensaje.

- Formas de la representación de los sujetos: la valoración sobre la acción de los sujetos y las instituciones.

- Tipos de la representación: los de la violencia de género contra las mujeres.

- Contextos de la representación: espacios donde la violencia es representada.

- Valoración de la representación: la calificación y/o adjetivación que recibe la violencia contra las mujeres por parte del medio.

- Sentido de la representación: objetivo que el contenido del discurso del medio expresa.

\section{Estrategia metodológica}

Para el estudio de la agenda sobre la violencia de género contra las mujeres y las niñas se ha considerado el análisis de contenido de la programación televisiva emitida durante una semana de 2006 -elegida aleatoriamente-, de los canales de mayor cobertura y rating en nuestro país: 2 y 5 (programación infantil) de Televisa, 7 y 13 de Televisión Azteca y 11 del Instituto Politécnico Nacional. 
TABLA 1

NÚMERO TOTAL DE REPRESENTACIONES DE LA VIOLENCIA DE GÉNERO CONTRA LAS MUJERES Y LAS NIÑAS EN LA TELEVISIÓN MEXICANA

\begin{tabular}{|c|c|c|c|c|c|c|c|c|c|c|c|c|}
\hline $\begin{array}{l}\frac{\tilde{d}}{\tilde{J}} \\
\stackrel{\Xi}{\tilde{U}}\end{array}$ & $\begin{array}{l}\frac{0}{0} \\
\frac{0}{0} \\
\frac{0}{0} \\
\text { E }\end{array}$ & 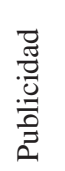 & 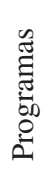 & $\begin{array}{l}\lambda \\
\frac{\pi}{\tilde{J}} \\
\frac{0}{2} \\
0 \\
0 \\
0\end{array}$ & $\begin{array}{l}0 \\
0 \\
0 \\
\vdots \\
0 \\
0 \\
0 \\
0\end{array}$ & 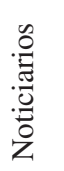 & $\begin{array}{l}\frac{a}{0} \\
\frac{0}{3} \\
\frac{0}{0} \\
0\end{array}$ & 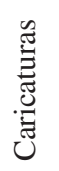 & $\begin{array}{l}\tilde{D} \\
\tilde{D} \\
\tilde{n}\end{array}$ & $\stackrel{\mathscr{0}}{0}$ & 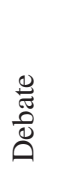 & $\stackrel{\widetilde{J}}{0}$ \\
\hline 2 & 121 & 111 & & 55 & & 44 & 17 & & & & & 348 \\
\hline 13 & 113 & 122 & & 75 & & 46 & 12 & & & & & 368 \\
\hline 5 & & 78 & & & & & 8 & 12 & 28 & 4 & & 130 \\
\hline 7 & & 61 & & & & 4 & 18 & & 10 & 8 & & 101 \\
\hline 11 & & 5 & & & & 16 & & & 5 & & 10 & 36 \\
\hline Total & 234 & 377 & & 130 & & 110 & 55 & 12 & 43 & 12 & 10 & 983 \\
\hline
\end{tabular}

Fuente: Elaboración propia.

\section{Hallazgos}

En total fueron analizadas 544 horas de programación, y se consideró, en todos los casos, el horario de 6 a 23 horas. El total de representaciones registradas fue de 983, distribuidas en los siguientes formatos: publicidad (377), telenovelas (234), programas de revista y concurso (139), noticiarios (110), películas (55), series (43), caricaturas (12), otros (12) y debate (10).

\section{Publicidad}

La publicidad no hace distinción de horarios para emitir contenidos que discriminan y violentan a las mujeres. Los más frecuentes son aquellos que las representan como objetos sexuales -como sucede en "Brozo y las mujeres que son como pecados", o en "Mforce" y en "Simi Power", donde las mujeres son obligadas a tener relaciones sexuales tras la ingesta de dichas fórmulas por su pareja masculina. También son comunes los comerciales que discriminan a las mujeres por razón de género: el de "Sony", donde la anciana es golpeada por unos jóvenes con un "balón"; el de "Coca-Cola", donde el niño se burla de su madre porque no sabe si ella se está arreglando o está viendo su vajilla nueva y el de "Aviacsa”, que anuncia ofertas con el 
eslogan "Manda a tu madre a volar". También es común representar a las mujeres como tontas y frívolas, en situaciones que las ridiculizan y las convierten en objeto de maltrato, como es el caso de la campaña de "Rexona".

Al mismo tiempo, esta investigación registró, en una cantidad no mayor a 25\%, la emisión de comerciales institucionales, provenientes de la Cámara de Diputados y el Senado de la República, que promovían la erradicación de la violencia de género contra las mujeres y las niñas, y, también, de los partidos Alianza por México y Revolucionario Institucional que, dado que eran tiempos electorales, concentraron una parte de su publicidad televisiva en la promoción de los derechos humanos de las mujeres.

\section{Telenovelas}

Las telenovelas constituyen uno de los géneros televisivos que más consumen las audiencias mexicanas. La forma en la cual es representada la violencia contra las mujeres y las niñas por este formato, alude a la reproducción de los estereotipos de género, en los cuales las mujeres, o caracterizan la figura moral de la trama -como buenas y sumisas, y como objeto constante de discriminación y violencia por parte de los demás- o son una amenaza para las otras y un peligro para el protagonista masculino y las tareas de dirección y decisión que este debe desempeñar en el ámbito público. Se reproduce también el estereotipo sobre la relación de competencia y descalificación, pero nunca de reconocimiento, entre mujeres.

En las telenovelas mexicanas, las agresiones e insultos contra las mujeres son presentados como parte de la conducta social aceptada. Los celos y amenazas por parte de los maridos, los hermanos y los hijos contra las esposas, las hermanas y las madres, constituyen el hilo conductor de las tramas, que en algunos casos incluyen escenas donde las mujeres son víctimas de violación y acoso sexual (Amor sin condiciones y Amores cruzados), de secuestro (Amor en Custodia), de amenaza de muerte (Amores cruzados) y de asesinato (Amor en custodia). Asimismo, y puesto que la violencia es representada como un problema de orden doméstico, la casa y la oficina son escenarios en los que las mujeres son encerradas, amenazadas y golpeadas. En el caso de la vio- 
lencia laboral, las mujeres son discriminadas por no ser bellas (Betty la fea) o por ser indígenas (El Manantial).

Las telenovelas apuntan al desamor como una de las principales razones del sufrimiento de las mujeres (Amores cruzados), con lo cual reivindican -suponemos que sin esa intención- una de las causas de la violencia psicológica, señaladas por la Ley General de Acceso de las Mujeres a una Vida Libre de Violencia. Mención especial merece la serie Lo que Callamos las Mujeres, producida por TV Azteca que, en principio, pareciera que apunta a la denuncia de la violencia de género. Sin embargo, el tratamiento estereotipado de los casos, que son presentados como problemas "de la casa", difícilmente contribuye a la conciencia social y a erradicar este problema.

\section{Programas de revista y concurso}

Los programas de concurso y revista (como Hoy, Buenas Tardes y Nuestra casa, Con sello de Mujer, Venga la alegría, Ventaneando, Tempranito, Temas de telenovela, Historias engarzadas, Va que va y Los 25 +, junto con las emisiones de El festival del humor y La parodia), constituyen la barra de entretenimiento de las principales televisoras mexicanas.

Chistes que ridiculizan a las mujeres -incluidas las espectadoras y también las que asisten como público-, insultos y agresiones físicas y sexuales contra las conductoras, constituyen las principales formas de discriminación que estos formatos utilizan contra las mujeres.

\section{Noticiarios}

La función social de los noticiarios, que es la de informar y de promover una conciencia sobre los problemas sociales, en este sentido no es asumida. Aun y cuando algunos de estos noticiarios-Primero Noticias y Noticiero - han sido analizados en el marco de casos relevantes, su atención en términos de cobertura y discusión del tema fue mínima, si la comparamos con otros casos.

Durante la semana de análisis, los noticiarios de Canal 2 dieron cobertura a las denuncias presentadas por las mujeres que fueron violadas por policías, en Atenco, y que evidenciaban maltratos físicos, psicológicos y abusos sexuales por parte de los miembros de la institución policial. Sin 
embargo, en la presentación de estas informaciones, los conductores se referían a ellas como "las supuestas mujeres violadas", lo que pone en duda la veracidad de su testimonio -corroborado ya por las autoridades. Así también, los noticiarios informaron de manera rápida y descontextualizada sobre casos de violencia sexual contra niñas, por parte de Cascos Azules de la ONU, y de un líder religioso acusado de abuso sexual.

En el caso de los noticiarios de TV Azteca (Hechos) existe una mayor denuncia de casos de violencia contra las mujeres en nuestro país, aunque la forma amarillista, trivial y superficial como se representa no va dirigida a erradicarla, sino a reproducirla.

Caso excepcional lo constituyen los noticiarios de la televisora pública, Canal 11, que realizan un tratamiento serio de las informaciones, aunque no profundizan en ellas. Por ello afirmamos que los programas de noticias de las principales televisoras de nuestro país no muestran interés por mantener en su agenda informativa los derechos humanos de las mujeres.

\section{Películas}

Clásicos del cine mexicano como Ustedes los Ricos son frecuentemente programados por las televisoras mexicanas. Estas, que son consideradas joyas de la época de oro, contienen distintas escenas en las cuales las mujeres son objeto de violencia física y psicológica por parte de los hombres de su entorno familiar y comunitario. En la misma línea, aunque de tiempos recientes, películas de manufactura nacional como $L a$ mujer de Benjamín, constituyen en sí mismas una apología de la violencia de género contra las mujeres. En esta se presenta como natural -con lo cual se justifica- el robo, el acoso sexual y el maltrato de mujeres.

Así también, las películas extranjeras programadas por la televisión abierta, muestran, sin representarlas como formas que violentan y discriminan a las mujeres, escenas en las cuales éstas son obligadas a casarse con los protagonistas (George de la selva, Corazón valiente), o son objeto de violación y víctimas de maltrato e incluso de violencia feminicida (Corazón valiente), o agredidas por su comunidad por ser "raras" (El diario de una princesa), u objeto de burlas e insultos por razón de género, es decir, por el hecho de ser niñas o mujeres (Mi encuentro conmigo mismo y Toy story). 


\section{Series}

Muchas series constituyen otro formato con un alto contenido misógino que violenta la integridad física y psicológica de las mujeres. Son los casos de Los Simpson, Lost, La niñera, Paso a paso, El Chavo del 8, Hércules, Smallville, Xeana y El señor de las bestias.

\section{Caricaturas}

Las caricaturas son el corazón de la barra programática de Canal 5, dado que tiene como principal target a niñas y niños. Toda la barra de caricaturas representó durante la semana del análisis alguna forma de agresión contra mujeres y en particular contra niñas, en la que se representa la violencia de género como un hecho natural y socialmente aceptado. En caricaturas como Las chicas superpoderosas, Dragon Ball, La mansión Foster, Los chicos del barrio, Tom y Jerry, Jimmy Neutrón y Los Thunderbirds, las niñas son llamadas con sustantivos y/o adjetivos como: "ladrona", "mentirosa", "boba", "pálida" y "fea".

\section{Otros}

En el rubro de "otros" cabe hacer mención especial del programa Incógnito, producido por Televisa que, si bien se transmite a las 11 de la noche, registra entre su audiencia un porcentaje significativo de niños y adolescentes. En este programa, su conductor, Facundo, acude comúnmente a bares y fiestas en las que expresa insultos, burlas y humillaciones que atentan contra la dignidad de las mujeres; algunos adjetivos con los que se dirige a ellas son: "cochina", "teibolera", "fodonga", "vieja", "güila", "gorda", “maldita”, “entrometida”, "fea", "tonta”, "aburrida", "porno", "solita" y "calientota".

\section{Programas de debate}

En esta categoría queremos hacer mención especial de los programas producidos y emitidos por la televisora pública Canal 11. Todos los programas registrados en este género, denuncian la violencia psicológica, sexual, económica y simbólica contra las mujeres y motivan una reflexión y toma de acción para erradicarla. Su barra programática está compuesta por: Diálogos en confianza, Primer Plano y Espiral. 
A lo largo de la semana de análisis, el programa Diálogos en confianza dedicó tres emisiones a la denuncia de casos de mujeres víctimas de la violencia sexual, económica, simbólica y psicológica ejercida por familiares, que en la mayor parte de los casos apuntaban al padre y al esposo. Se trata de los pocos programas que asumen su responsabilidad social, informando de las causas que originan la violencia de género y apuntando a soluciones. En este sentido, anima a las mujeres a denunciar, vía telefónica e Internet, la violencia de que son objeto. Por otro lado, los integrantes de Primer plano dedicaron un segmento de su emisión semanal a cuestionar a las autoridades por no ejercer acciones en contra de los policías que violaron a las mujeres en Atenco. Por último, el programa Espiral abrió una mesa de debate sobre la violencia de género contra las mujeres, en el que abundó sobre su definición, causas y consecuencias, y contó con la colaboración de Alicia Elena Pérez Duarte (fiscal especial de la Procuraduría General de la República; PGR), Lucía Lagunes (agencia de noticias Comunicación e Información de la Mujer; CIMAC), Laura Salinas (Universidad Autónoma de México; UAM) y Rosa María Navarro (Cámara Nacional de la Industria de Transformación; CANACINTRA).

Así, de las televisoras analizadas, Canal 11 es la única que declaradamente mantiene en su agenda programática asuntos relacionados con los derechos humanos de las mujeres.

\section{CONCLUSIONES}

A la vista de lo expuesto, es preciso anotar una serie de reflexiones preliminares. En primer lugar, y al tratársele como un problema aislado, trivial y de orden doméstico, observamos que el discurso televisivo privilegia la representación de las mujeres y las niñas como víctimas de la violencia, y en géneros como las telenovelas, la publicidad o los programas de revista, son ellas las responsables de la violencia de la cual son objeto. Casi nunca se identifica al ejecutor de los actos violentos, y además no existe un interés de estos programas por señalar a los responsables. Al papel que deben jugar las autoridades se alude muy poco, y casi nunca a su responsabilidad en la erradicación de este problema. 
En este marco, todos los tipos de violencia contra las mujeres y las niñas son representados en el discurso televisivo, pero dicha enunciación no se hace, lamentablemente, con el objetivo de identificar los tipos y las causas de la violencia, ni mucho menos con el de erradicarlos, más bien con el de reproducirlos. Las que más prevalecen son las violencias física, psicológica, sexual y simbólica.

En relación con los ámbitos de la violencia contra las mujeres y las niñas, podemos concluir que este hecho representa, desde la perspectiva del discurso televisivo, un problema individual, aislado y privado que sucede comúnmente en espacios privados (la casa, la escuela, la oficina) y no en públicos, lo que contribuiría a que se le tratara como un problema de orden público y social.

En tal cuadro, no se representa a la violencia contra las mujeres y las niñas como un problema, por lo cual las enunciaciones que los programas de televisión hacen no van dirigidas a un conocimiento ni toma de conciencia social, sino a su reproducción. De esta manera, el objetivo que el contenido del discurso televisivo expresa, tiende a trivializar el problema, más no a identificarlo y mucho menos a denunciarlo.

Debemos añadir que la difusión acerca de las formas de discriminación y violencia contra las mujeres y las niñas se ha multiplicado en el discurso televisivo, pues hoy en día no es sólo a través de los formatos clásicos encargados de esta labor, como es el caso de los noticiarios, sino también a través de programas populares (talk shows, series, telenovelas). Sin embargo, no basta con visualizar: es necesario conocer cómo se persibe este problema y si la manera de informar sobre él induce a una lectura consciente, responsable y crítica, o más bien arbitraria y superficial.

En este tenor, no podemos dejar de reconocer que los medios de comunicación, y especialmente la televisión, si bien no determinan a las audiencias qué pensar, sí influyen en la agenda de temas sobre los cuales la sociedad discute, por lo que es pertinente afirmar que los medios son corresponsables de la apatía social y la ignorancia que de este problema existe.

El objetivo de este trabajo es el de sumar claves para erradicar la violencia que se ejerce contra las mujeres y las niñas en el mundo, condición para que accedan a una vida libre de discriminación, opresión, sujeción y maltrato, es decir, al reconocimiento y respeto pleno a sus 
derechos humanos. En este tenor, la contribución de los mass media se reconoce como indiscutible, por lo cual consideramos que, por lo que a nuestra responsabilidad toca, una deuda que los comunicólogos y las comunicólogas tenemos pendiente es la de generar estrategias que, de manera contundente, motiven cambios en el quehacer de las instituciones mediáticas para que contribuyan efectivamente a la solución de esta problemática.

Por esta razón, hacemos un llamado a los comunicólogos y las comunicólogas del país y del mundo a dirigir el producto de sus investigaciones en beneficio de los demás. Si logramos realizar esta tarea podremos empezar a trazar un panorama afirmativo de vida, basado, como nos lo ha enseñado Marcela Lagarde, en el reconocimiento y respeto pleno de los derechos de los humanos y las humanas.

\section{Bibliografía}

Abric, J. C. (1994). Pratiques sociales et représentations. París, Francia: PUF.

Álvarez, E. (2008). Violencia contra las mujeres desde una perspectiva de los derechos humanos. Ponencia presentada en el VII Diplomado sobre Violencia Familiar y Derechos Humanos. México: Instituto de Investigaciones Jurídicas de la UNAM.

Carrillo, R. (1992). La violencia contra la mujer: un obstáculo para el desarrollo. Nueva Jersey, EE. UU.: Fondo de las Naciones Unidas para la Mujer.

Comisión Especial para Conocer y dar Seguimiento a las Investigaciones Relacionadas con los Feminicidios en la República Mexicana y a la Procuración de Justicia Vinculada (2006). Investigación diagnóstica sobre violencia feminicida en la República Mexicana. México: LIX Legislatura de la Cámara de Diputados.

De Lauretis, T. (1987). Technologies of Gender. Essays on Theory, Film and Fiction. Bloomington, Indiana, EE. UU.: University Press.

Flores-Palacios, F. (1996). Representación social: género y salud mental. En N. Calleja \& G. Gómez-Peresmitré (Comps.), Psicología social: investigación y aplicaciones en México (pp. 131-162). México: Fondo de Cultura Económica, Biblioteca de Psicología, Psiquiatría y Psicoanálisis. 
Gobierno Federal (2007). Ley General de Acceso de las Mujeres a una Vida Libre de Violencia. México: Diario Oficial de la Federación.

Ibáñez, T. (1988). Ideologías de la vida cotidiana. Barcelona, España: Sendai.

Instituto Oficial de Radio y Televisión de España (2002). Mujer, Violencia y Medios de Comunicación. Dossier con el contenido del informe sobre el tratamiento informativo de los medios de comunicación a la violencia de género. Madrid, España: Instituto de la Mujer/IORTVE.

Kaufman, M. (1999). Las siete P's de la violencia de los hombres. Consultado en diciembre de 2008. Disponible en: http://hombressinviolencia.org/docs/Las\%20Siete_Ps\%20de\%201a\%20Violencia\%20de $\% 2010$ \%20Hombres.pdf.

Lagarde, M. (2006). Por la vida y la libertad de las mujeres, fin al feminicidio. En D. Russell \& R. Harmes (Eds.). Feminicidio: una perspectiva global (pp. 5-12). México: Universidad Nacional Autónoma de México, Centro de Investigaciones Interdisciplinarias en Ciencias y Humanidades, Comisión Especial para Conocer y dar Seguimiento a las Investigaciones Relacionadas con los Feminicidios en la República Mexicana y a la Procuración de Justicia Vinculada.

Lori, H. (1994). Violencia contra la mujer. La carga oculta sobre la salud. Washington: Organización Panamericana de la Salud, Oficina Sanitaria Panamericana, Oficina Regional de la Organización Mundial de la Salud.

McCombs, M. \& Donald, Sh. (1972). The Agenda-Setting Function of Mass Media, The Public Opinion Quarterly, 2 (36), 176-187.

Millán, M. (1996). Género y representación: el cine hecho por mujeres y la representación de los géneros, Acta Sociológica, 16, enero-abril, 169-183.

Moscovici, S. (1976). Psychologie des representations sociales, $\mathrm{Ca}$ hiers Vilfredo Pareto. 14, 409-416.

Now Legal Defense and Education Fund (2005). Recuperado 10 de julio de 2005, en http//www.nowldelf.org

Pedraza, C. (2008). Fuera de lugar: la representación social del futbol femenil en el discurso televisivo. México: Facultad de Ciencias Políticas y Sociales de la UNAM. 
Seager, J. (2001). Atlas del estado de la mujer en el mundo. Madrid, España: Akal.

Wolf, M. (1994). La investigación de la comunicación de masas. Crítica y perspectiva. México: Paidós.

Fecha de recepción: 02/05/2009. Aceptación: 28/08/2009. 